\title{
Wound Healing Property of Carica papaya Stem in Albino Rats
}

\author{
Marzha Ancheta ${ }^{1 *}$, Liwayway Acero ${ }^{2}$ \\ ${ }^{1}$ San Beda College, Manila Philippines. \\ 2 Department of Natural Sciences, San Beda College, Manila Philippines. \\ *Corresponding author. Tel.:02-8321159; email: marzha.ancheta@yahoo.com, lilyacero1@yahoo.com \\ Manuscript submitted December 19, 2015; accepted April 6, 2016. \\ doi: 10.17706/ijbbb.2016.6.2.68-74
}

\begin{abstract}
Carica papaya has been known for its many potential uses. The fruit is a part of the human diet and it is also use in cosmetics and medicalfield. Almost all parts of the plant was explored for its medicinal property, however the stem which remains in the field after harvest was seemingly neglected, thus this study. Carica papaya stem were dried cut and turned to ointment form. The final product was applied to inflicted wounds of five Albino rats which are assigned in the treatment group (treatment 2).Ten Albino rats served as experimental animals. They are randomly assigned in two groups. The first group, or treatment 1 , ( 5 animals) as the control. Inflicted wounds of Albino rats in treatment 1 was applied by the usual antiseptic (Betadine). The second group, treatment 2 served as the experimental animals where the ointment from papaya stem was applied. Initial wound size and mean size of the wound every two days interval showed no significant result. The final wound size in millimeter after fifteen days showed significant result. The result revealed that the stem of Carica papaya has the wound healing property in Albino Rats. The result of this study attested that even the stem of Carica papayacan be utilized as a source of herbal plant, specifically to heal wounds.
\end{abstract}

Key words: Carica, papaya, wound, healing.

\section{Introduction}

The Philippines was endowed with indigenous herbal plants. Many of these plants have not yet been explored and some are neglected and remain underutilized. Papaya is a popular tropical fruit in the Philippines and it is one of the most common plants found in a typical Filipino backyard. Papaya is a rich source of nutrients such as vitamin C. carotene and flavonoid. Papaya is commonly added as whitening agent in various beauty and cosmetic products such as facial cream, lotion and soap. Carica papaya is the sole species in the genus Carica of the plant family Caricaceae. It originated to the tropics of America and is considered as one of the most popular and economically important plants in the Philippines. According to the Philippine Council for Agriculture, Aquatic and Natural Resources Research (PCAARRD), Philippines ranked eight in the world's papaya production [1].

Although papaya is a good source of antioxidant nutrients it is now being exploited for their aesthetic values. Papaya is not just for aesthetic purposes, it has many potential towards alternative treatment. With extensive research papaya can be considered as an important agent against many diseases [2]. Recent studies have shown that C. papaya leaf extract significantly increased platelet count and anti-sickling property. Moreover, C. papaya dried seeds are said to have anthelmintic activity where study evaluated air-dried papaya seed on human intestinal parasites showing efficacious results without significant side 
effects. Laboratory studies have shown that papaya seed contraceptive effect has been demonstrated in male monkeys and possibly have contraceptive effect in adult male humans [3]. Different parts of the papaya plant including fruit, leaves, stems, seeds, flower and roots have been used as ingredients in alternative medicine. For instance, decoction of the center part of the root is used as a digestive and tonic, and used to cure dyspepsia and papaya leaves are used as a treatment for malaria because it is said to have an anti-malarial effect, but these treatments are not yet scientifically proven [4]. Papaya seeds are also used as folkloric treatment to wounds. Wound is the most common injury. Wound is an injury involves the breaking of the skin caused by cuts, animal bites, burns, splinter, thorns or puncture. A break in the skin could cause infections including pus, swelling, redness and even fever. Recent studies have stated that fresh papaya has a wound healing property. One of the most important ingredients in papaya is the enzyme papa in. Papain is a product used in treating wounds, which can be extracted from the latex of papaya tree [5]. Latex mostly found in unripe fruits, stem and leaves contains proteolytic enzymes, papa in and chemopapain, glutamine cyclotransferase, chymopapain A, B and C, peptidase A and B and lysozymes [6].

\subsection{Objectives of the Study}

This study determines the wound healing property of the papaya stem, in terms of size of the wound until full epithelialization and the progress of the wound until final healing and contraction.

\section{Materials and Methods}

\subsection{Materials}

In the preparation of papaya stem ointment the following materials were used; Carica papaya stems, vegetable oil, white wax, digital balance, beaker. electric stove, saucepan, spatula, strainer, cheesecloth and ointment container.

The experimental animals includes; Albino rats, cages, water bottle, feeding trough, rodent feeds, water gloves, masks, and laboratory gown.

For the wound making, the following materials were used: Albino rats, laboratory gown, gloves, masks and surgical cap, holding tray, clean cloth, Ketamine Hydochloride (General Anesthesia), shaver, surgical scissors, Betadine, forceps, syringe, alcohol and cotton balls.

\subsection{Methods}

\subsubsection{Acclimatization of animals}

Experimental animals were ten (10) healthy young male albino male rats, weighing between one hundred to one hundred fifty grams (100-150 g). These rats were randomly selected assigned in two groups (treatment 1 as the control and treatment 2 treated with papaya ointment) to avoid bias in the result. They were housed in groups of two animals each, in standard cages for an acclimatization period of seven (7) days or one (1) week before the commencement of experiment. During this period the animals had free access to standard pellet diet and water adlibitum in an ambient temperature of $\left(24 \pm 2{ }^{\circ} \mathrm{C}\right)$; a standard laboratory condition.

\subsubsection{Experimental layout}

The experimental groupings were treatments 1 and 2. Treatment 1 was the animals in the control group while treatment 2 was the animals who were subjected to papaya stem ointment. Animals were caged according the layout shown in Table 1 during the entire experiment to avoid wound irritation.

\subsubsection{Preparation of Carica papaya stem ointment}

Fresh papaya stems were collected locally. Dirt was removed from the stems by rinsing with clean water. The stems were air-dried for five (5) days without direct sunlight exposure and cut into 1-inch pieces. Using a beaker 
and digital balance the dried papaya stems and oil were measured. One (1) part dried papaya stem and two (2) parts oil were mixed and heated over a low heat for 45 minutes to one (1) hour until the oil is very green [7]. The oil was strained using cheesecloth and the infused oil was heated again with the white wax until melted as shown in Fig. 1 a) and Fig. 1 b).

Table 1. Experimental Layout

\begin{tabular}{ll}
\hline \hline T1 (Control Group) & T2 (Experimental Group) \\
\hline \hline T1S1 & T2S1 \\
\hline T1S2 & T2S2 \\
\hline T1S3 & T2S3 \\
\hline T1S4 & T2S4 \\
\hline T1S5 & T1S5 \\
\hline \hline
\end{tabular}
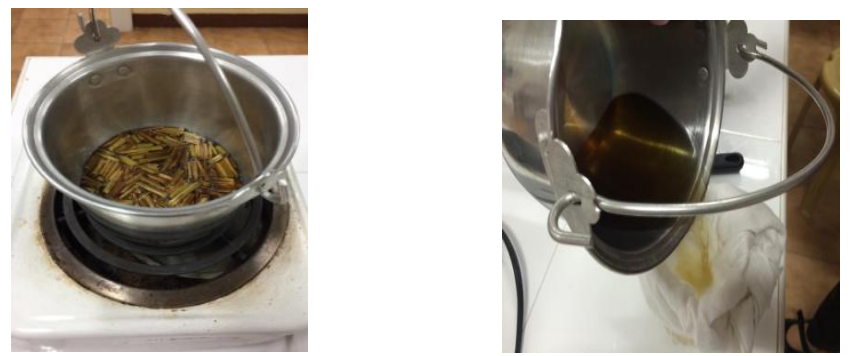

Fig. 1 a). Boiling of Carica papaya stem and oil. Fig. 1 b). Straining of Carica papaya stem and oil.

\subsubsection{Wound infliction/creation}

Each Albino rat was anesthesized with intraperitoneal ketamine hydrochloride $(50 \mathrm{mg} / 10 \mathrm{ml})$ before creating the incised wound. This was done with closed supervision of a licensed veterinarian. The dorsal skin was shaved and cleaned with Betadine prior to the experiment (see Fig. 2 a) ).The wound was made on the back, dorsal thoracic region using a surgical scissors. An open full-thickness wound that was approximately $10 \mathrm{~mm}$ long was cut up to the level of subcutaneous adipose tissue by means of surgical blade and surgical scissors [7] as shown in Fig. 2 b). After the wounding process, each Albino rats was caged individually and wrapped with sterilized cloth to avoid hypothermia due to anesthesia.

All wounds were left uncovered. Albino rats in treatment Group 2 (Experimental) was treated with prepared papaya stem ointment daily, at the dosage of $100 \mathrm{mg} / \mathrm{kg} /$ day to $500 \mathrm{mg} / \mathrm{kg} /$ day [8]. Albino rats in treatment 1 (Control) was left untreated.
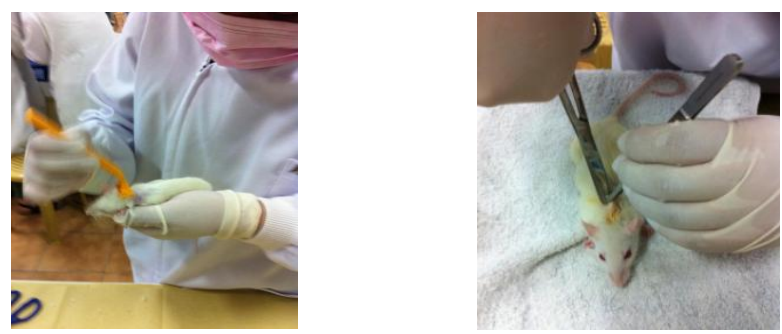

Fig. 2 a). Shaving and cleaning prior to wound infliction. Fig. 2 b). Wound infliction.

\subsubsection{Data gathered and statistical analysis}

Initial wound size in millimeter was measured before the start of the study and the final wound size after 15 days when the wound already healed using a caliper. Mean size of the wound every two (2) days interval was determined by measuring the wound every two (2)days. The data gathered was statistically evaluated through 
standard T-test. A statistical analysis was performed using Microsoft Excel, version 2013. A significant difference was achieved when the value of t-statistics is greater than t-critical value. On the other hand the progress of wound healing was observed by taking pictures every five days interval.

\section{Results and Discussion}

\subsection{Initial Wound Size of the Experimental Animals in Millimeters}

Table 2 shows the initial wound size of the experimental animals. Animals in treatment 1 had a mean wound size of $10 \mathrm{~mm}$ while in treatment 2 had a mean wound size of $10.2 \mathrm{~mm}$. Comparing the mean size of inflicted wound, there was a negligible difference which means the wounds of control and experimental animals were almost equal. T-test was used to analyze difference in the mean size of the wound, and it showed no significant difference which implied that the wound size in the control and experimental groups were almost equal on the start of the study to avoid bias on the result.

\subsection{Mean Wound Size of the Experimental Animals in Millimeters every Two Days Interval}

Table 3 shows the mean size of the wound in millimeters per treatment in 2 days interval. Animals in treatment 1 had a total mean size of $5.63 \mathrm{~mm}$. while animals in treatment 2 had a mean wound size of $3.53 \mathrm{~mm}$. T-test was used to evaluate the significant difference between the two groups and it showed no significant difference on the wound size of the experimental animals. This could be explained by the fact that the epithelialization is still incomplete within 2 days interval. This could be supported by the study on the use of methanolic extract of papaya leaves in wound. It showed that the wounds completely healed in treated group (epithelisation period) $14 \pm 2$ days where as in the control animals $24 \pm 2$ days [9].

Table 2. Initial Wound Size in Millimeters

\begin{tabular}{lcccccccc}
\hline & $\begin{array}{c}\text { Animal } \\
1\end{array}$ & Animal 2 & Animal 3 & Animal 4 & Animal 5 & Total & Mean & T-test \\
\hline $\begin{array}{l}\text { Treatment 1 - } \\
\text { control }\end{array}$ & 7 & 12 & 10 & 11 & 10 & 50 & 10 & $\begin{array}{l}\text { Not sig. } \\
\text { T-stat } \\
-0.17<\text { Tcrit } \\
2.30\end{array}$ \\
$\begin{array}{l}\text { Treatment 2- } \\
\text { with }\end{array}$ & 10 & 12 & 12 & 9 & 8 & 52 & 10.2 \\
$\begin{array}{l}\text { papaya } \\
\text { ointment }\end{array}$ & & & & & & & \\
\hline \hline
\end{tabular}

Table 3. Mean Size of the Wound at Two Days Interval in Millimeters

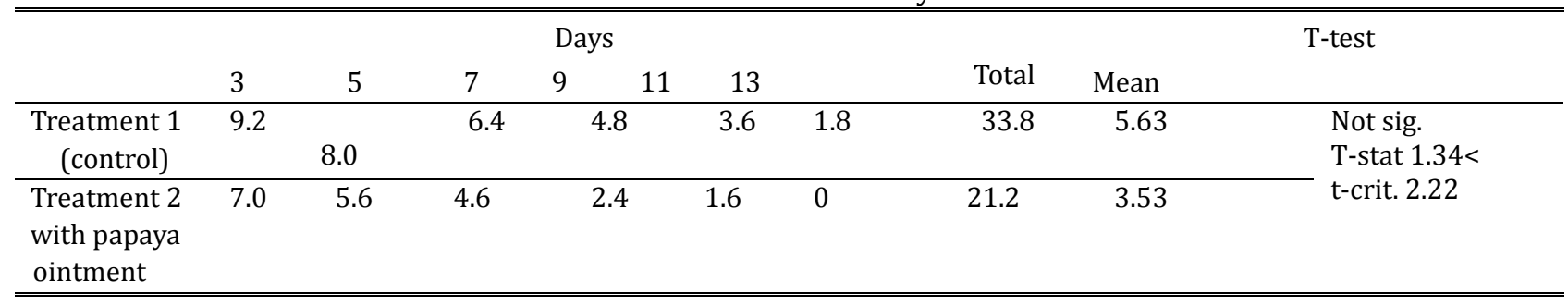

\subsection{Final Wound Size of the Experimental Animals in Millimeters}

Table 4 shows the Day 15 wound size of the experimental animals. Animals in treatment 1 had a mean wound size of $1.4 \mathrm{~mm}$. while animals on treatment 2 had a mean wound size of $0 \mathrm{~mm}$. T-test was used to evaluate the significant difference between the two groups and it showed a significant difference on the wound size of the experimental animals. At this point of the experimental period, wounds in Treatment 1 are still in healing process while the wounds of animals in treatment 2 were already healed. It further 
shows that Albino rats in Treatment 2 showed more advanced healing process than Treatment 1 animals, making papaya stem ointment effective as a healing agent. The results mentioned above revealed a significant difference in favor of treatment 2 (with papaya stem ointment). The stem, green fruits and leaves contain copious white milky latex. The latex of the papaya plant and its green fruits contains two proteolytic enzymes, papain and chymopapain [10]. Papain which is present in the papaya latex is responsible for producing less scarring of the burn wounds as it produced cleaner wounds [11]. A study on the wound healing Activity of Carica papaya aqueous leaf extracts in rats revealed same result. It was concluded that aqueous extract of papaya significantly accelerate wound healing compare to control and it is recommended to be useful as a dressing agent for wounds [12]. Another reason which can be used to explain the effectiveness of C. papaya is the presence of alkaloid, which is known to be a highly antimicrobial agent [13]. The results implied that Carica papaya has advanced healing effect. It can be supported by the study on health benefits of papaya where it stated different active components (papain and alkaloids) of papaya that are beneficial for the body [14].

Table 4. Final Wound Size in Millimeters after 15 Days

\begin{tabular}{lcccccccc}
\hline & Animal & Animal & Animal & Animal & Animal & \multicolumn{2}{c}{ T-test } \\
& 1 & 2 & 3 & 4 & 5 & Total & Mean & \\
\hline $\begin{array}{l}\text { Treatment } 1 \\
\text { (control) }\end{array}$ & 0 & 3 & 2 & 0 & 2 & 7 & 1.4 & $\begin{array}{l}\text { Significant } \\
\text { T-stat } \\
2.33>\text { T-crit } \\
\text { Treatment 2 }\end{array}$ \\
$\begin{array}{l}\text { (with papaya } \\
\text { ointment) }\end{array}$ & 0 & 0 & 0 & 0 & 0 & 0 & 0 & \\
\hline \hline
\end{tabular}

Table 5. Progress of Wound Healing Every 5 Days Interval

\begin{tabular}{lllll}
\hline \hline Days & Day1 & Day 5 & Day 11 & Day 15 \\
\hline & & & & \\
\hline $\begin{array}{l}\text { Treatment } 1 \\
\text { (control) }\end{array}$ & & & & \\
\hline
\end{tabular}

\subsection{Pictures of Progress of Wound Healing}

Table 5 shows the progress of wound healing every 5 days interval. Visually, Albino rats in treatment 2 exhibited a higher wound contraction compared to the Albino rats in the control group (treatment 1). The same findings was obtained in the study of Aqueous extracts of unripe versus ripe of Carica papaya fruits where latex that contain papain like in the papain in the stem, were studied to compare their effects on wound healing in rats. The extracts in a dose of $100 \mathrm{mg} / \mathrm{kg}$ were applied toexcision and dead space wound models using streptozotocin-induced diabetic rats observed for 10 day. The treatments exhibited $77 \%$ reduction in wound area compared with controls (59\%) [13].

\section{Conclusion and Recommendation}


Findings of this study revealed that Carica papaya stem has wound healing property.

Further studies should be explored on the possibilities of using other methods on turning the product into cream or lotion in different concentrations and different types of administration to heal burn and other skin injuries

\section{Acknowledgment}

The authors acknowledge their invaluable administrators, professors from San Beda College, College of Arts and Sciences. Dr. Tessie R. da Jose-Dean, Dr. Christian Bryan Bustamante-Vice Dean and Dr. Fedeliz S. Tuy-Associate-Vice Dean, for their constant encouragements. From the College of Medicine, Dr. Pacifico Calderon for the guidance on the use of Animal House. Other mentor, Dr. Eduardo Lorico, for his expertise, closed supervision and assistance in handling the laboratory animals.

\section{References}

[1] ABSPII. (2013). Project: Papaya. RingspotVirus Resistant Papaya.

[2] Rivera-Pastrana, D. M., Yahia, E. M., \& Gonzales-Aguilar, G. A. (2010). Phenolic and cartenoid profiles of papaya fruit and their contents under low temperature storage. Journal of Science of Food and Agriculture, 90(14), 2358-2368.

[3] Lohiya, N. K., et al. (2007). Chloroform extract of carica papaya seeds induces long-term reversible azoospermia in langur monkey. Asian Journal of Andrology, 4(1), 17-26.

[4] Dharmarathna, S. L., Wickramasinghe, S., Waduge, R. N., Rajapakse, R. P., \& Kularatne, M. (2013). Does carica papaya leaf extract increase the platelent count? An experimental study in a murine model. Asian Pacific Journal of Tropical Biomedicine, 3(9), 720-724.

[5] Ortega, M, (2011). Effects of Proteolytic Enzyme and Fiber of Papaya on Human Digestive Health.

[6] Yogiraj, V., et al. (2014). Carica papaya linn: An overview. International Journal of Herbal Medicine, 2(5), 01-08.

[7] Shetty, S., Udupa, S., \& Udupa, L. (2008). Evaluation of antioxidant and wound healing effects of alcoholic and aqueous extract of Ocimum sanctum Linn in rats. Evidence-Based Complementary and Alternative Medicine, 5(1), 95-101.

[8] Nitika, J., \& Rupesh, T., (2011). Practices in wound healing studies of plants. Evidence-Based Complementary and Alternative Medicine, 2(11), 1-17.

[9] Morton, J. (2011). Fruits of warm climates: Papaya. Purdue University 20534 SW 92 Ct.Miami, FL, 33189.

[10] Nayak, B. S., Ramdeen, R., Adogwa, A., Ramsubhag, A., \& Marshall, J. R. (2012). Wound-healing potential of an ethanol extract of Carica papaya (Caricaceae) seeds. International Wound Journal, 9(1), 650-655.

[11] Shuid, A. M., et al. (2005). The effects of carica papaya linn. Latex on the Healing of Burn Wounds in Rats, 3(2), 39-47.

[12] Teixaeira, S. J. A., Rashid, Z., Nhut, D. T., Sivakumar, D., Gera, A., Souza, J. M. T., \& Tennant, P. F. (2007). Papaya (Carica papaya L.) biology and biotechnology. Tree and Forestry Science and Biotechnology, 1(1), 47-73.

[13] Mohamood, A., Sidik, K., \& Salmah, I. (2005). Wound-healing activity of carica papaya L. aquaeous leaf extract in rats. International Journal of Moleculer Medicine and Advance Sciences, 1(4), 398-401.

[14] Anuar, N. S., Zahari, S. S., Taib, I. A., \& Rahman, M. T. (2008). Effect of green and ripe carica papaya epicarp extracts on wound healing and during pregnancy. Food Chem Tox Journal, 46(6), 2384-2389.

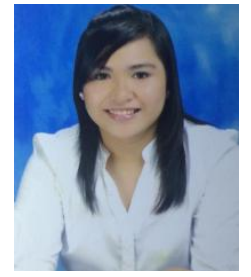

Marzha Ancheta was born on April 5, 1995, in Manila Philippines. She got her BS human biology student from San Beda College, Manila, Philippines. Her research interests are in alternative medicine. 


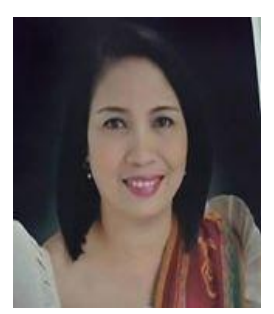

Liwayway H. Acero is a member of Asia Pacific Chemistry, Biology, Environment, Engineering Society, editorial member for Global Science and Technology Forum, Palawan Scientist. She is one of the Technical panel of the International Journal of Food Engineering and Technology. Educational background: Doctor of Education major in Educational Management from Palawan State University on March 2003. She conducted her dissertation as research student at Okayama University Graduate School Education in Japan on March to June 2000. She got her diploma in science teaching -major in biology in 2009 from the University of the Philippines-Open University in Los Banos Laguna. She received her Master of Science degree in agricultural education major in agricultural education minor in Plant Science (Agronomy) from the Western Philippines University in Aborlan, Palawan, Philippines on April 1993. She got her Bachelor of Science degree in Agriculture (cum laude), major in Animal science and minor in Plant Science (agronomy) from the Western Philippines University in Aborlan, Palawan Philippines on April 1986.

She is an associate professor and the chairperson of the Department of Natural Sciences, College of Arts \& Science in San Beda College, Mendiola, Manila, Philippines. Prior to her employment in San Beda College in Manila, she had served as professor for 20 years in Western Philippines University in Puerto Princesa City, Palawan, Philippines. She handled several administrative works aside from teaching profession. She served as assistant dean of Western Philippines University, Puerto-Princesa Campus, and Director for Instruction, Department Chairperson of the Education Department chairperson of the Agribusiness Department \& chairperson for the thesis committee. She had 13 publications. Ten of which are international publications. 